\title{
MENSURAS Y DESMENSURAS DEL MUNDO, HISTORIA(S) ENTRE CIENCIA Y ARTE
}

\author{
Pierre Gautreau \\ Laboratoire PRODIG, Institut de Géographie, Université Panthéon Sorbonne. \\ (Paris, Francia) \\ ORCID: https://orcid.org/0000-0003-1174-2002 \\ pierre.gautreau@univ-paris1.fr
}

En la práctica del cientifico entrenado para medir, evaluar, dimensionar los bechos sociales y el mundo que nos rodea, adoptar sendas alternativas a lo que recomienda la Academia puede aportar reflexividad, entusiasmo, dinámicas colectivas, y muchas veces abrir nuevas interrogaciones para la disciplina misma. Es uno de estos experimentos que relata este breve texto, nacido de trabajos multidisciplinarios sobre el catastro de tierras de Buenos Aires en el siglo XIX. Cansados del exceso de mediciones, cartografías y mensuras topográficas, un grupo de personas propone con algo de provocación desarrollar prácticas de «desmensura» del mundo. Las páginas que siguen detallan las herramientas y los procedimientos a utilizar para desarrollar con bumor y seriedad dicha empresa entre ciencia y arte.

PalabRas ClaVE: Catastro, agrimensor, mensura, cartografía, topografía.

\section{MEASURES AND UN-MEASURES OF THE WORLD. (HI)STORIES BETWEEN ART AND SCIENCE}

For the scientists trained to measure, to evaluate, to dimensionate social facts and the world around us, adopting alternative paths to academicism can provide reflexivity, enthusiasm, collective dynamics, and often opens new questions for the discipline itself. It is one of these experiments this short text relates, an experiment born from multidisciplinary research on the land cadastre of Buenos Aires during the 19th century. Tired of the excess of measurements, cartographies and topographic measurements of Earth, a group of people propose with some bumor to develop «un-mesurement» practices of the world. The following pages detail the tools and procedures to be used to develop this ability between science and art with both bumor and seriousness.

KEYWORDS. Land cadastre, land surveyor, measure, cartography, topography. 
En algún lugar de las afueras de París, refieren la historia. Dos veces por año, en las laderas del valle del Sena, se reúne una extraña comitiva de «desmensuradores» equipados de teodolitos, cadenas de agrimensor, mojones de topógrafo. Todo en sus atuendos haría pensar que están levantando algún catastro de la zona, si no fuera por lo heterogéneo del grupo que evoca más al malón pampeano que la rigurosa labor de los que miden la propiedad de la tierra: allí hay niños y ancianos, altos y petisos, gordos y flacos, mujeres y hombres. Algunos meditan tirados sobre el césped mientras otros trabajan con esmero. Hasta se puede observar racimos de desmensuradores corriendo a los gritos tras un cometa [cerf-volant], cuando el viento no basta para levantarla por los aires. Hay quienes dicen que no es casualidad si entre ellos encontramos a un colega de Juan Carlos Garavaglia, un geógrafo que supo perderse entre historiadores, allá por el 2010, para estudiar con él la construcción del Catastro de tierras de la provincia de Buenos Aires.

FIgURA 1. Agrimensores en la Pampa, siglo XIX. Autor: J. L.Pallière, en Escenas Americanas. Reproducción de cuadros, aquarelas y bosquejos. Litografía Pelvilain, 1864.

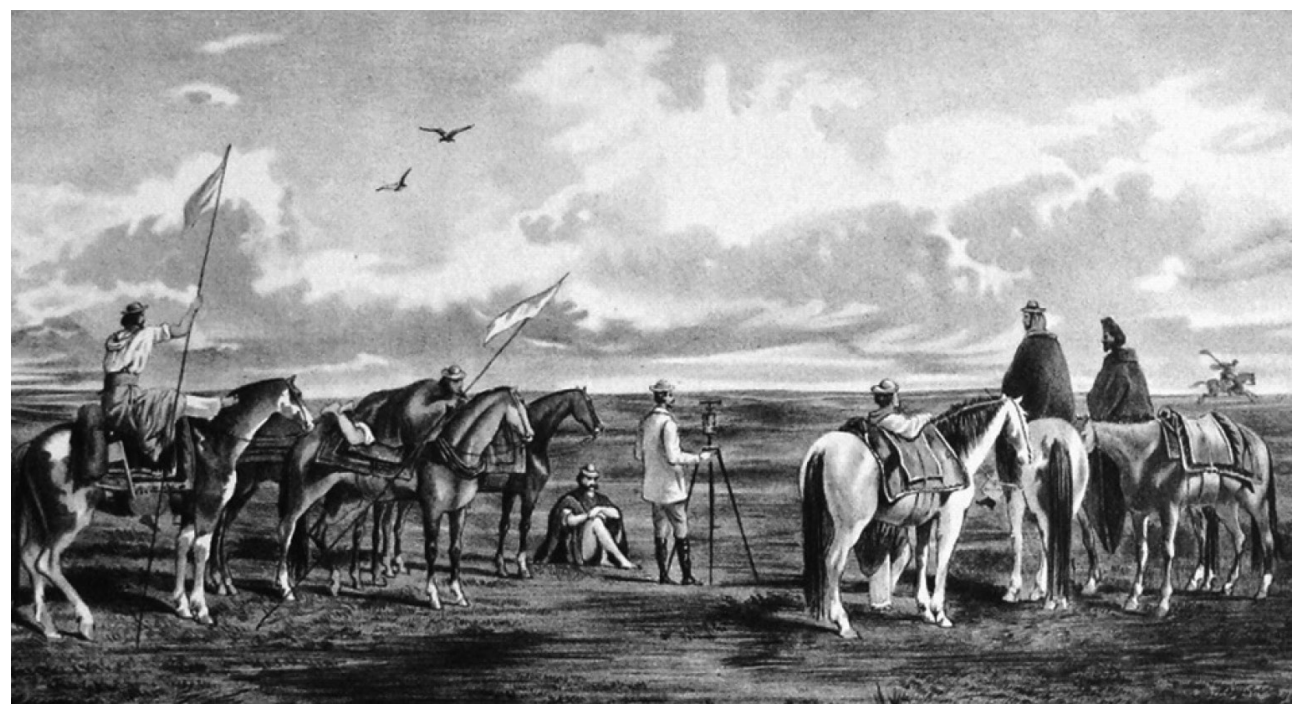

A más de 12.000 kilómetros del Río de la Plata, y con aires mucho menos austeros que los que adoptaban los agrimensores del siglo XIX, ¿qué hacen, en definitiva, estas personas desperdigadas por un descampado a poca distancia de la capital francesa (cf. fig. 1)? Se juntan con el simple propósito de «aliviar» la superficie terrestre de tantos mapas que la midieron, calcularon sus formas y sus curvas, establecieron distancias entre sus puntos, delinearon fronteras, demarcaron apropiaciones. Para eso, como quien desanda caminos, hay que realizar el acto contrario al de cartografiar, o sea des-cartografiar. Para darse objetivos más humildes que el de dar por tierra con cuanto mapa se hizo desde los albores de la cartografía, decidieron ensañarse con el catastro de tierras, en Francia 
símbolo de la propiedad privada. Aún no está muy claro qué es lo que mueve en lo más hondo a estos individuos en plena desmensura, más allá del placer de compartir horas de des-trabajo y de intercambiar trucos para hacerlo bien. Probablemente, una creencia común que acumulación de datos no equivale a mejor gobernanza de la tierra y de su gente. Que la carrera mundial para medir en tiempo real la superficie terrestre y sus cambios, en nombre de la lucha contra la crisis ambiental, puede traer tantos problemas como promete soluciones. Sin duda, no se trata de una crítica generalizada al hecho de mapear, tan conscientes son los desmensuradores que el mapa, y el catastro en particular, también pueden servir de amparo al débil frente a la arbitrariedad del poderoso. La «desmensura» se parece en muchos aspectos a lo que los filósofos llaman una «experiencia de pensamiento», preguntando a través de sus actos qué podría ser un mundo donde no pasáramos la mayor parte de nuestro tiempo en mediciones diversas. Es por ello que esta práctica joven prefirió hasta ahora, lejos de las teorizaciones, proponer una serie de «gestos» que vamos a detallar a continuación para ilustración de nuestros lectores.

1. Comer el catastro. Se trata de la más famosa de las prácticas de desmensura, por su fácil implementación y fuerte simbolismo (figuras 2 a 4). Es necesario equiparse con papel comestible (del que se usa para decorar postres, o para hacer ostias), de una pluma de acero para escribir, y de tintas también comestibles de las que se usan para teñir tortas. Bastará con copiar sobre el papel comestible una porción de catastro, local o lejano, dejar secar el conjunto sobre una cuerda para ropa, antes de comerlo.

FIGURA 2. Calcando el catastro sobre papel comestible con tintas para repostería.

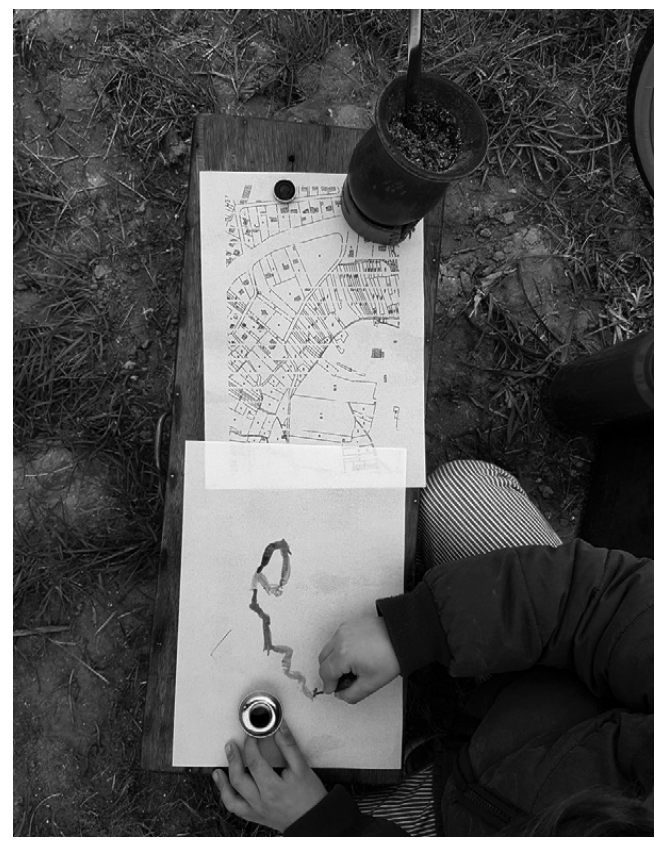


Figura 3. Antes de comer al catastro, es preciso dejarlo secar en una cuerda.

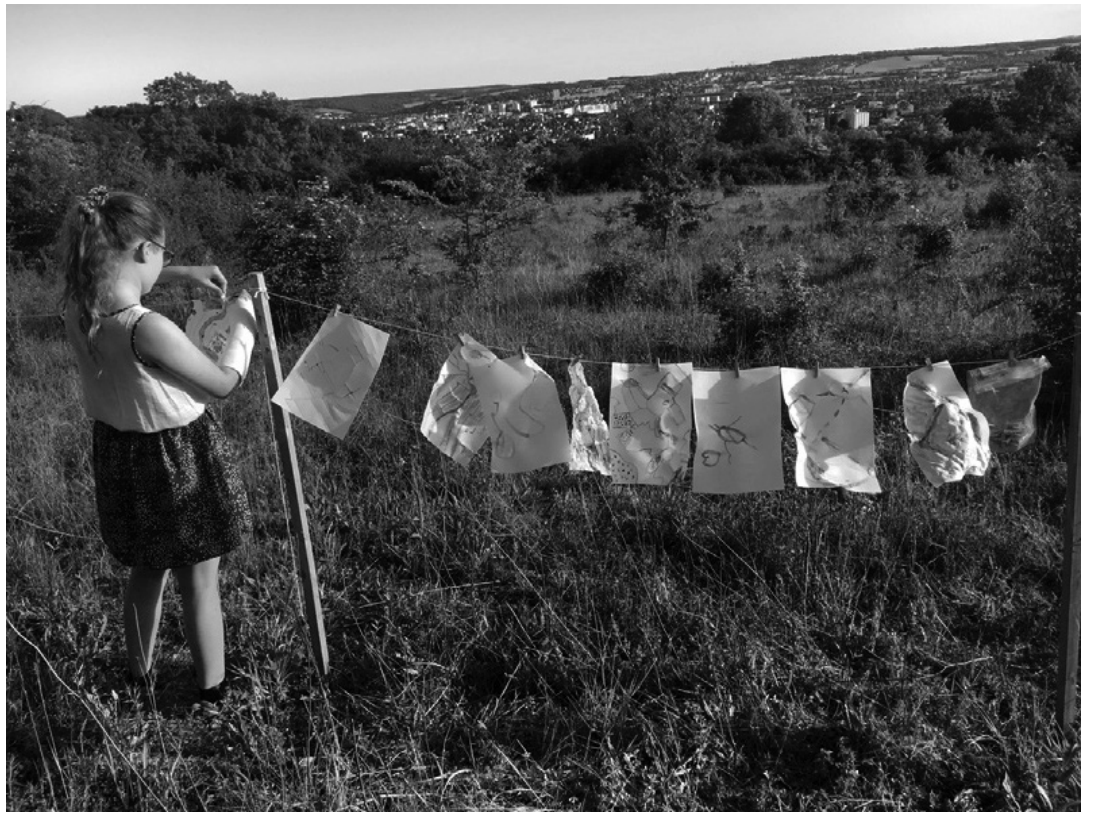

FiguRA 4. Comiendo el catastro tras una larga jornada de desmensura.

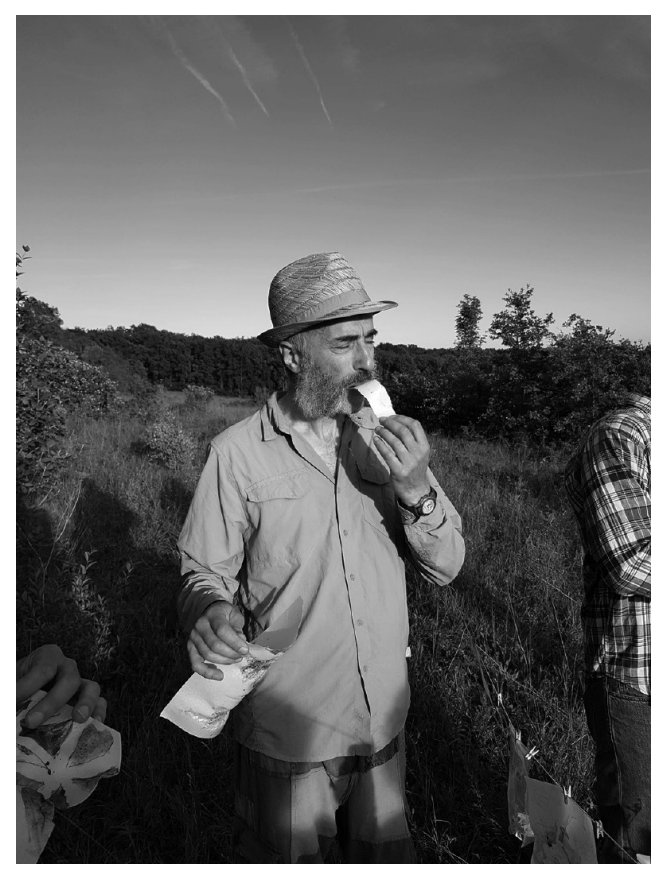


2. Aliviando los mojones. Siendo que el mayor «peso» de la cadastración descansa sobre los mojones que separan las parcelas, basta con inventar sistemas que tiren estos mojones hacia arriba para aliviarlos de dicho peso. En la actualidad, el sistema más popular consiste en atar una cometa al mojón, en tiempos de viento (figura 5). En ausencia de viento, un método alternativo utiliza pequeños globos aerostáticos de papel, inflados con el calor de una vela.

FIgURA 5. Atado a un mojón en un día ventoso, esta cometa permite aliviar el peso del catastro sobre la Tierra.

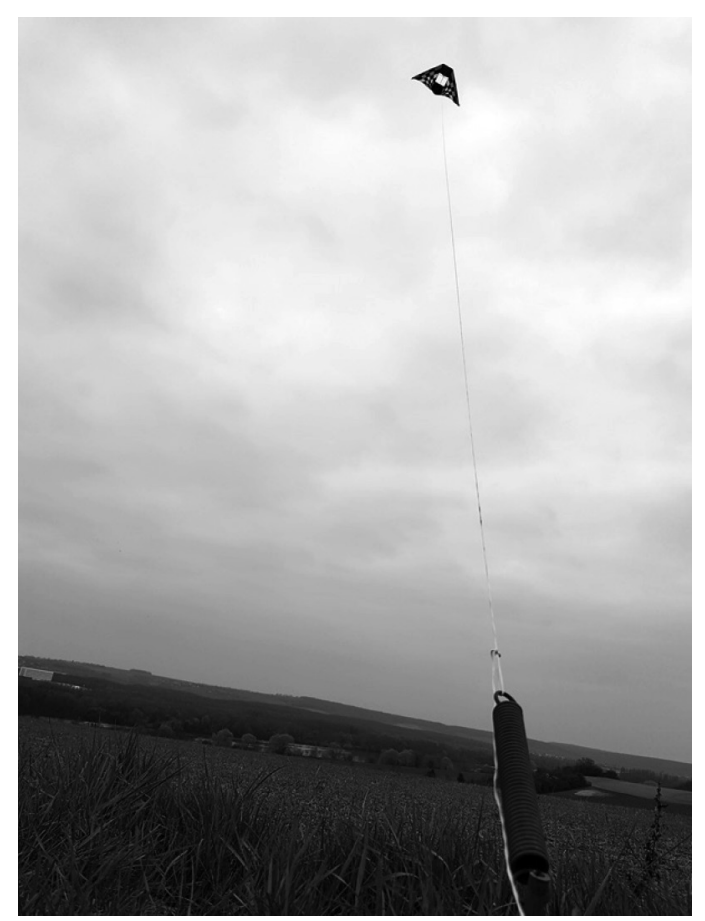

3. Mediciones suaves e imprecisas. De forma algo más sutil que los dos métodos anteriores, éste no propone una simple desconstrucción (simbólica) del catastro, sino una subversión de la lógica de precisión que constituye su legitimidad histórica. Para ello, basta con utilizar los instrumentos del agrimensor, pero asegurándose de que midan mal. Por ejemplo, usamos una legítima cadena de topógrafo de 10 metros usada para calcular distancias en el terreno, pero cambiando uno de sus eslabones de metal por una tira de goma (figura 6). De esta forma la cadena se estira aleatoriamente y nos aseguramos de que el resultado sea falso en referencia a las normas geométricas convencionales. Entre otras mediciones suaves e imprecisas solemos usar el teodolito (la herramienta fundamental de los que hacen mapas), pero acostados en el suelo, con colchón y almohada. Esta 
posición garantiza un uso aproximativo del aparato, y resultados cartográficos acordes (figura 7).

FIgURA 6. El tercer eslabón (parte izquierda) de esta cadena de topógrafo fue reemplazado por hilo de goma para garantizar la inexactitud de la medida de las distancias.

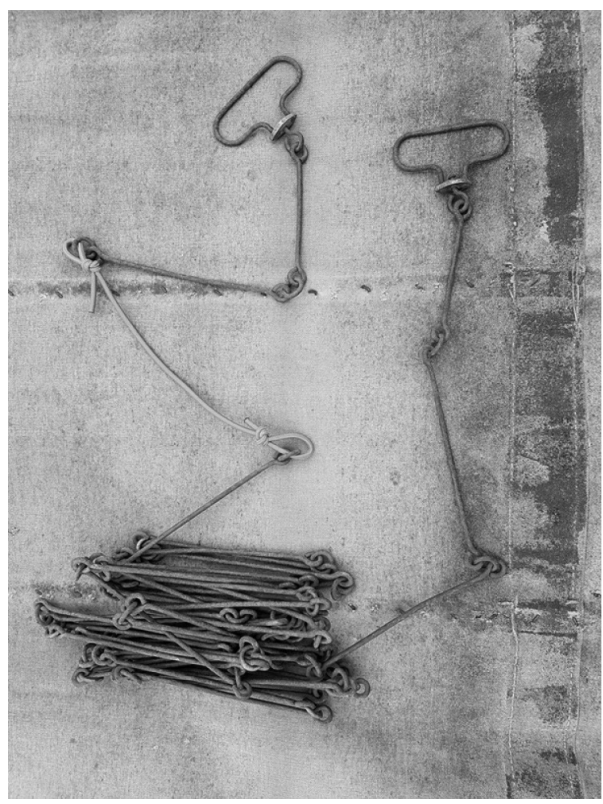

FIGURA 7. Acostado en su almohadita, el pequeño desmensurador mide de forma imprecisa gracias a su teodolito.

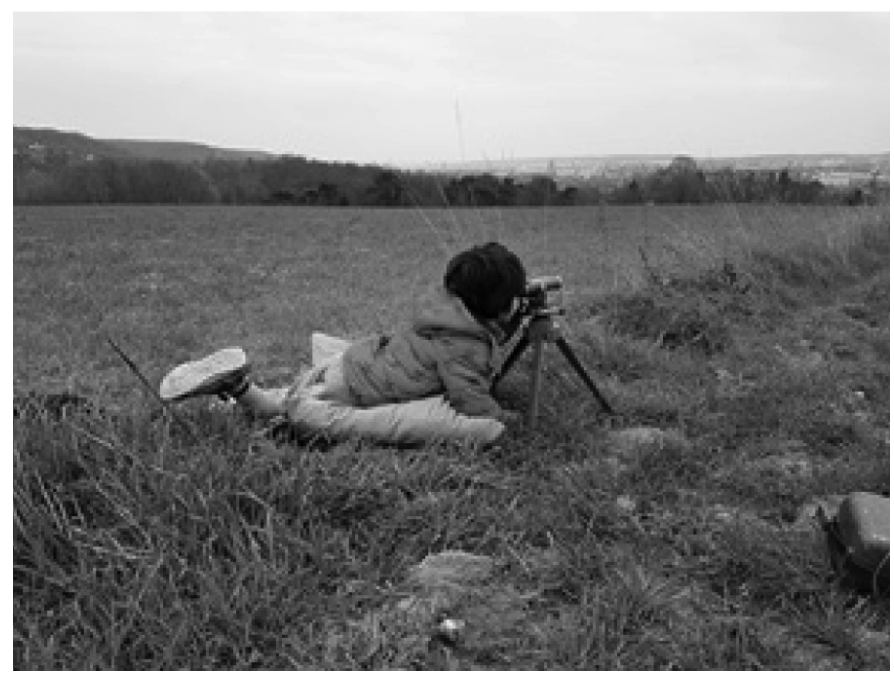


4. Saturación parcelaria. Un método recientemente incorporado al repertorio de los desmensuradores echa mano de pequeños mojones temporarios usados comúnmente por los agrimensores para ubicar ángulos de parcelas en el terreno. Su color —naranja - y su forma evocan irresistiblemente a una flor, y de ahí nació la idea de crear campos de flores con estos mojones temporarios. En las sesiones de desmensura, se suele desde entonces cubrir con cientos de «flores» partes del terreno, como forma de «saturar» el catastro: tantos mojones juntos no pueden sino confundir a los que buscan en el catastro claridad y precisión (figura 8).

FIGURA 8. Mojones de mensura se transforman en campo de flores.

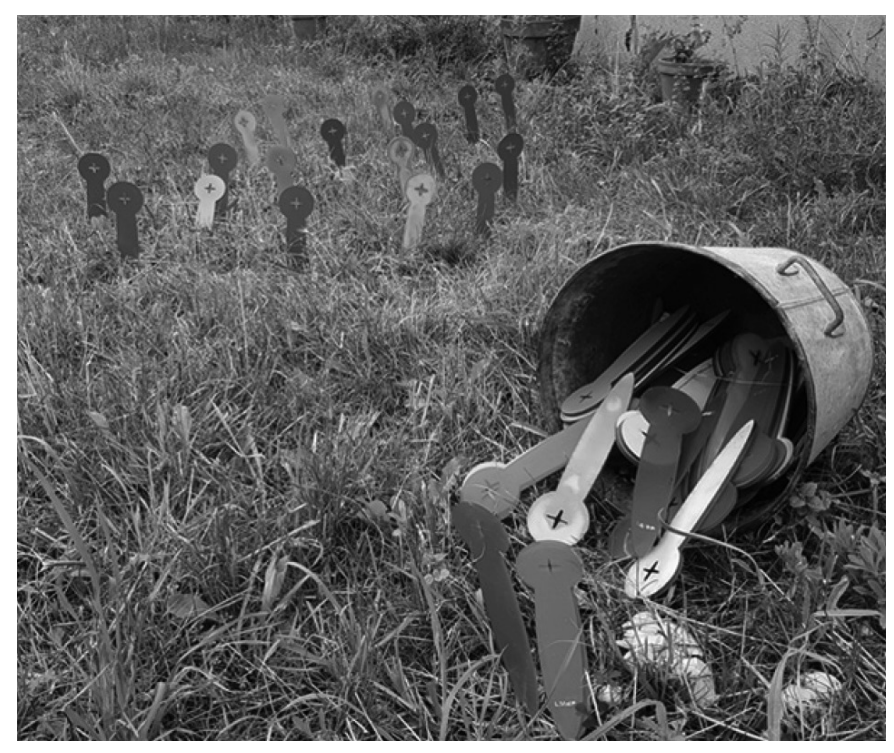

5. Teodolito-bar. La última herramienta inventada para la desmensura es una copia fiel del ancestro del teodolito, llamado popularmente en el Río de la Plata «plancheta». Usada hasta la década del 50 en Argentina y Uruguay para medir fácilmente grandes campos, la plancheta está formada por un trípode al cual se le superpone una tabla de pequeñas dimensiones donde se dibuja en el campo el mapa de la propiedad. Esta tabla tiene que estar permanentemente en posición horizontal. Se ideó para el teodolito-bar un sistema de medición de esta horizontalidad en base a un pequeño recipiente, el cual tiene que estar rellenado con vino. Para ello, el instrumento posee en su caja tres botellas de vino, que se van usando para calibrar el teodolito durante toda la operación cartográfica (figura 9). 
FIgURA 9. Evaluación de la horizontalidad del teodolito-bar.

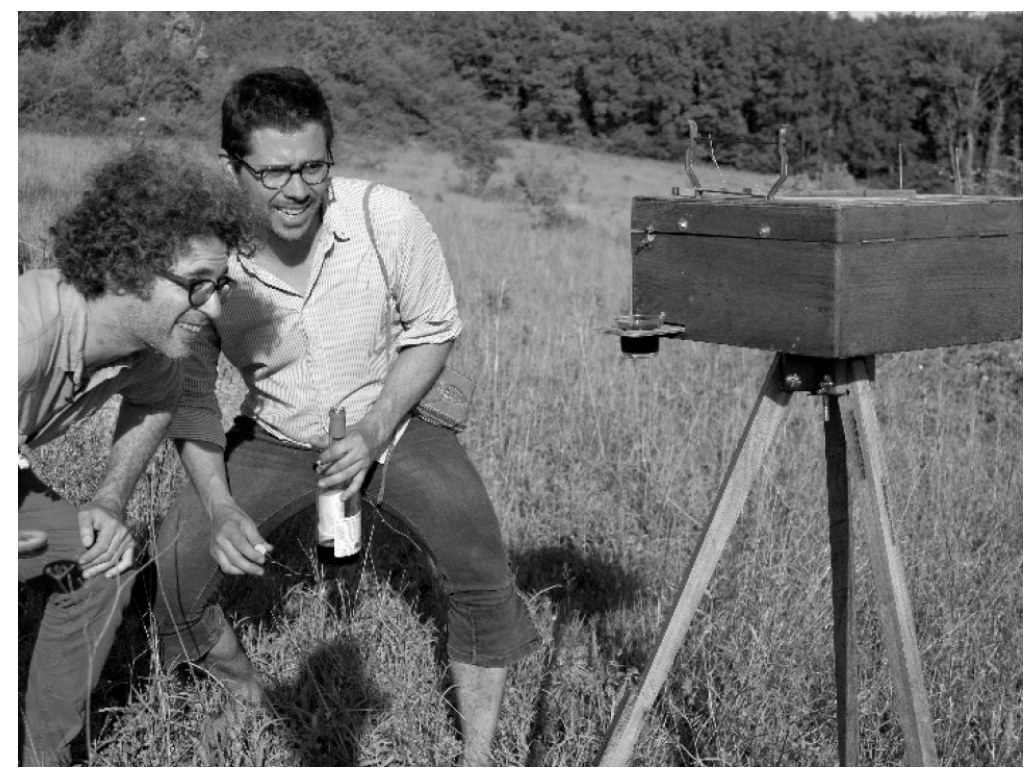

Información adicional. Para mayor esclarecimientos sobre la «desmensura» del mundo, se recomienda consultar el siguiente sitio web, <https://www.instagram.com/desarpentage/> (con el aplicativo Instagram, buscar <@desarpentage $>$ ). Para participar en las futuras sesiones de desmensura, proponer nuevas técnicas, etc, contactarse con el autor de esta nota. 